\title{
ISOLATION AND ANTIMICROBIAL ACTIVITY OF RHAMNOLIPID (BIOSURFACTANT) FROM OIL-CONTAMINATED SOIL SAMPLE USING HUMIC-ACID SALTS-VITAMIN AGAR
}

\author{
Kalyani A.L.T ${ }^{1}$, Naga Sireesha $G^{2}$, Aditya A.K.G ${ }^{3}$, Girija Sankar G \\ ${ }^{1}$ Research Scholar and Corresponding Author, AU College of Pharmaceutical Sciences, Pharmaceutical Biotechnology \\ Division, Andhra University, Visakhapatnam 530003, India. \\ ${ }^{2}$ M. Pharm Student, AU College of Pharmaceutical Sciences, Pharmaceutical Biotechnology Division, Andhra University, \\ Visakhapatnam 530003, India \\ ${ }^{3}$ M. Pharm Student, AU College of Pharmaceutical Sciences, Pharmaceutical Biotechnology Division, Andhra University, \\ Visakhapatnam 530003, India \\ ${ }^{4}$ Professor, AU College of Pharmaceutical Sciences, Pharmaceutical Biotechnology Division, Andhra University, \\ Visakhapatnam 530003, India
}

\begin{abstract}
In this study, actinomycetes were isolated from the soil sample contaminated with petroleum oil in Naval Dockyard near Visakhapatnam. The isolate was identified as Streptomyces coelicoflavus comprising $16 \mathrm{~S}$ rDNA sequence. Ten isolates of soil actinomycetes were initially screened in humic acid-salts vitamin agar plates. Soil organic matter is generally rich in humic acid and fluvic acid. Humic acid is an important ingredient for the extraction of biosurfactant producing actinomycetes. In the present study, humic acid substances used for screening of biosurfactant producing Actinomycetes were extracted by using soil organic matter. Humic substances were extracted by treating this organic soil with alkalis like dilute sodium hydroxide. The ten isolates were further grown in Kim's medium, containing olive oil as the sole source of carbon, for extracellular biosurfactant activity by oil spreading method. Out of these ten, only three isolates namely, NDYS-1, NDYS-3, NDYS-4, showed promising biosurfactant activity compared to the standard, sodium laryl sulphate. These three promising isolates were further screened for their biosurfactant activity by using Para film-M method, Emulsification index and Phenol $\mathrm{H}_{2} \mathrm{SO}_{4}$. Out of these three, only NDYS-4 showed maximum biosurfactant activity for the above tests. The result showed that the extracellular surface active agent produced by the isolate NDYS-4 was Rhamnolipid in nature, and was further confirmed by orcinol assay taking L-rhamnose as standard. Then crude extract obtained from this isolate was used in contact bioautography for antibacterial activity. It was observed that as the antibacterial activity increased, the biosurfactant activity also increased and vice versa.
\end{abstract}

Keywords: Humic acid, Fluvic acid, Organic matter, Biosurfactant, Bioautography -***

\section{INTRODUCTION}

Humic substances are considered as the most important constituents of soils. These are formed by the decomposition of plant and animal residues by microorganisms. The humic substances play an important role in increasing biosurfactant productivity and soil fertility. In organic soils, this humic substance forms a large part of the total reserve of organic matter up to $80-90 \%[1,2]$.

Biosurfactants are a chemically diverse group of surfaceactive molecules produced by various groups of microorganisms that may belong to yeast, bacteria, filamentous fungi, plants and animals [3, 4]. Surfactants manufactured by the chemical industry pose environmental problems because of their toxicity and resistance to degradation [5]. Currently, there is interest in replacing these chemical surfactants with biological surfactants $[5,6]$.

Biosurfactants have potential advantages over chemical surfactants, because of their low toxicity, high biodegradability, high selectivity and specific activity, and availability of its raw material where biosurfactant can be produced from low-cost raw materials, which are available in large quantity [5-8].

Biosurfactants are categorized mainly by their chemical composition and their microbial origin [9]. In general, biosurfactants are classified into lipopeptides, lipoproteins, glycolipids, polymeric fattyacids, phospholipids, neutral lipids and particulate biosurfactants [10]. 
Glycolipid biosurfactants are the most promising, owing to their high productivity from renewable resources and versatile biochemical properties. Among the glycolipids, the best known rhamnolipids are trehalolipids and sophorolipids [11].

Rhamnolipids have several potential industrial and environmental applications including the production of fine chemicals, the characterization of surfaces and surface coatings and as additives [12]. They can be efficiently used in handling industrial emulsions, biodegradation and detoxification of industrial effluents, control of oil spills, and in bioremediation of contaminated soils [13-15].

Pharmaceutically, antibiotic resistance is a serious and widespread problem i.e., hydrophobic antibiotics are those cells which do not take them up. Rhamnolipids are one of the main biosurfactants, tested for the uptake of hydrophobic antibiotics in-vivo to enhance their activity $[16,17]$.

The objective of this study was to isolate soil actinomycetes from oil contaminated soil in naval dock yard to screen for extracellular biosurfactant activity and their identification methods.

\section{MATERIALS AND METHODS}

\subsection{Isolation of Biosurfactant Producing Actinomycetes}

\subsubsection{Selection of Soil Samples}

The soil sample was collected in sterile plastic bags from Naval Dockyard in Visakhapatnam. Soil mixed with petrochemicals was taken for screening of biosurfactant producing microorganisms.

\subsubsection{Selective Isolation of Biosurfactant Producing}

\section{Actinomycetes}

Collected soil sample was air dried at room temperature for 1 week, then was treated at $55{ }^{\circ} \mathrm{C}$ in a hot air oven for $3 \mathrm{~h}$, and then was stored at room temperature in sterile bags. The sample was labelled as NDYS. About one gram of soil sample was weighed and transferred to $50 \mathrm{ml}$ of sterile water, and then was placed on rotary shaker at $120 \mathrm{rpm}$ for $30 \mathrm{~min}$. After 30 min, serial dilutions were made from these solutions up to $10^{-10}$ order by taking $1 \mathrm{ml}$ and diluting it to $10 \mathrm{ml}$ with distilled water.

Humic acid supplemented actinomycetes selective medium was used for specially obtaining biosurfactant producing actinomycetes [18]. 100 $\mu$ l aliquots of the appropriate dilution were applied to Humic acid-Salts-Vitamin agar plates which the $\mathrm{pH}$ was adjusted to 7.0 .
These plates were supplemented with Rifampicin $(50 \mu \mathrm{g} / \mathrm{ml})$ and cycloheximide $(50 \mu \mathrm{g} / \mathrm{ml})$ and were incubated at $28^{\circ} \mathrm{C}$ for 7 days for the growth of actinomycetes colonies. Humic acidsalts-vitamin agar medium was used to isolate specifically the biosurfactant producing actinomycetes [19].

After 7 days of incubation, actinomycetes colonies were preliminarily selected based on colony morphology and small portion of colony streaked on Bennet's agar medium with the help of sterile inoculating loop. These strains were preserved in refrigerator at $4^{0} \mathrm{C}$ for further identification studies.

\subsubsection{Laboratory Synthesis of Humic Acid}

$50 \mathrm{~g}$ of soil sample was taken in a conical flask, and was washed with $50 \mathrm{ml}$ of $0.1 \mathrm{M} \mathrm{HCl}$. Humicacid from the soil sample was extracted by adding $100 \mathrm{ml}$ of $0.5 \mathrm{M} \mathrm{NaOH}$ and keeping this flask on an orbital shaker at $120 \mathrm{rpm}$ for $2 \mathrm{~h}$. Subsequently, the extracted solution was filtered and was adjusted to $\mathrm{pH} 1$ by concentrated $6 \mathrm{M} \mathrm{HCl}$. As a result of the $\mathrm{pH}$ adjustment, a solid precipitate representing the crude humic acid fraction was produced, while the crude fulvic fraction remained in the filtrate. The obtained crude humic acid was dissolved in $0.5 \mathrm{M} \mathrm{NaOH}$ and was reprecipitated by acidification using $6 \mathrm{M} \mathrm{HCl}$. The solid precipitate was redissolved in $0.5 \mathrm{M} \mathrm{NaOH}$ to obtain the humic acid solution. This solution was dried in the hot air oven to convert it into humicacid crystals. These crystals were used in the preparation of Humicacid-salts-vitamin agar medium [20].

\subsection{Screening for Biosurfactant Activity}

Isolates were sub-cultured from the working stocks, and were incubated at $28{ }^{\circ} \mathrm{C}$ for 7 days. After incubation, the microbial growth from each slant was suspended in $2 \mathrm{ml}$ of sterile distilled water, and was transferred in to $50 \mathrm{ml}$ of Kim's medium in a $250 \mathrm{ml}$ Erlenmeyer flask [21]. This flask was then incubated on a rotary shaker for 7 days at $28{ }^{\circ} \mathrm{C}$. After incubation, the content of the flask was centrifuged at 7000 rpm for 20min, and was filtered. This cell-free supernatant was used for experimentation in the following preliminary tests for identifying the presence of biosurfactant.

\subsubsection{Oil Spreading Method}

$10 \mu \mathrm{l}$ of crude oil was added to the surface of $40 \mathrm{ml}$ distilled water in a petri dish to form a thin layer of oil. Then $10 \mu \mathrm{l}$ of culture supernatant were gently placed on the centre of the oil layer. In few seconds, a clear zone was formed on this oil layer, which indicated the presence of biosurfactant in the supernatant. The diameter of this clearing zone on the oil layer correlates to the effectiveness of surfactant activity [22].

\subsubsection{Para Film-M test}

One drop of Bromophenol blue indicator was added to $2 \mathrm{ml}$ of cell-free supernatant. $10 \mu 1$ of this sample was carefully placed like a drop on parafilm-M with a micropipette. The shape of 
this drop on the surface was inspected after 1 min. Sodium lauryl sulfate and phosphate buffer $(\mathrm{pH}$ 7.0) were used as positive and negative controls respectively. If the drop becomes flat, it indicates the presence of biosurfactant. If it remains in dome shape, it indicates the absence of biosurfactant [23].

\subsubsection{Emulsification Index}

Emulsifying capacity of the biosurfactant was evaluated by emulsification index (E24). The E24 of the culture sample was determined by adding $6 \mathrm{ml}$ of kerosene, $4 \mathrm{ml}$ of water and $1 \mathrm{ml}$ of the cell-free broth in a test tube, and was vortexed at high speed for $2 \mathrm{~min}$, and allowed to stand for 24h. The E24 index is given as percentage of the height of emulsified layer $(\mathrm{cm})$ divided by the total height of the liquid column $(\mathrm{cm})$. The percentage of emulsification index was calculated by using the following equation [24, 25].

$$
\text { E24 }=\frac{\text { Height of emulsion formed }}{\text { Total height of solution }} * 100
$$

\subsubsection{Phenol-Sulphuric Acid Method}

To $1 \mathrm{ml}$ of cell free supernatant, $1 \mathrm{ml}$ of $5 \%$ phenol was added. To this mixture, $2-5 \mathrm{ml}$ of concentrated sulphuric acid was added drop by drop, until characteristic colour was developed. Development of orange colour indicated the presence of glycolipids [26].

\subsection{Conformation Tests for Rhamnolipid}

\subsubsection{Orcinol Assay}

$400 \mu \mathrm{L}$ of cell-free supernatant was taken and its $\mathrm{pH}$ was adjusted to 2 by adding $2 \mathrm{~N} \mathrm{HCl}$ to separate the Rhamnolipid. To this, 750 $\mu 1$ of diethyl ether was added and mixed thoroughly to extract Rhamnolipid in to an organic layer. This organic layer was collected. Solvent addition and extraction were repeated twice. Ether fractions were pooled and dried by evaporation. $400 \mu \mathrm{l}$ of $\mathrm{pH} 8$ phosphate buffer was added to the remaining precipitate (this equals to $1 \mathrm{x}$ dilution). $2.7 \mathrm{ml}$ of orcinol was added to $300 \mu 1$ of sample.

$300 \mu \mathrm{l}$ of phosphate buffer, taken as blank, was also treated with $2.7 \mathrm{ml}$ of orcinol reagent. Standard solutions of LRhamnose between $50-250 \mu \mathrm{g} / \mathrm{ml}$ were prepared with phosphate buffer, and were treated with orcinol reagent. Samples, standards and blank were boiled for $20 \mathrm{~min}$, and test solutions were left in dark for $35 \mathrm{~min}$ to cool down to room temperature. Then, optical density was measured at $421 \mathrm{~nm}$. The rhamnolipid concentrations were calculated from standard curves prepared with L-rhamnose and were expressed as rhamnose equivalents [27, 28].

\subsection{Time Course of Biosurfactant Production}

The time course of biosurfactant production was followed in batch cultures at optimum conditions. This experiment was designed for 10 days starting from the log phase to stationary phase under submerged culture conditions [29]. The resultant cell-free supernatant was removed by filtration followed by cold centrifugation at $10,000 \mathrm{rpm}$ at $4{ }^{0} \mathrm{C}$ for $20 \mathrm{~min}$. The supernatant was analyzed for biosurfactant production by orcinol assay.

\subsection{Extraction of Crude Biosurfactant}

Biosurfactant was recovered from the filtrate by acid precipitation method [30]. To $5 \mathrm{ml}$ of cell free supernatant, $2 \mathrm{~N}$ $\mathrm{HCl}$ was added to adjust its $\mathrm{pH}$ to 2 , then was placed in refrigerator at $4^{0} \mathrm{C}$ for overnight so that Rhamnolipid is precipitated. Ethyl acetate was added to the filtrate in the ratio of $1: 1(\mathrm{v} / \mathrm{v})$ and was shaken vigorously for 1 hour for complete extraction. The ethyl acetate phase that contains biosurfactant was separated from the aqueous phase.

It was evaporated to dryness and the residue was washed twice with ethyl acetate, later dried. Thus obtained compound was dissolved in phosphate buffer $\mathrm{pH} 8$ and used to determine antimicrobial activity and to perform bioautography for the screened isolate NDYS-4.

\subsubsection{Bioautography}

The crude extract was loaded on to pre-coated Thin Layer Chromatographic (TLC) plates with the capillary tubes and eluted using $50 \%$ ethyl acetate, $50 \%$ hexane as mobile solvent system. The developed plates were dried under a stream of fast moving air for an hour to remove traces of solvent on the plates. Bacterial (S.aureus, E.coli) suspension of $24 \mathrm{~h}$ cultures grown on nutrient agar slants were freshly prepared in sterile distilled water. Then plating was done using inoculated nutrient agar.

After solidification, the air-dried TLC plates were placed onto the media with the help of sterilized forceps. These plates were kept in refrigerator for one hour for diffusion. After marking, TLC plates were removed. This whole process was carried out aseptically in a Laminar flow cabinet. Thereafter, these plates were incubated overnight at $37^{\circ} \mathrm{C}$ for bacterial growth. A control was also kept using solvent alone. The inhibition zone diameters were measured and noted [31].

\subsection{Identification of the Strain NDYS-4}

The different characteristics of the new isolate or unidentified organism were determined in adequate detail, for its identification and classification. The major characteristics which were determined are as follows: 


\subsubsection{Macroscopic Examination}

The isolates were grown on $20 \mathrm{ml}$ of Benett's agar medium by pouring on a petri plate, and were incubated at $28^{\circ} \mathrm{C}$ for 7 days, and were visually observed for the evaluation of colony morphology, such as colony size, shape, surface texture, arrangement of cell masses and margin.

\subsubsection{Microscopic Examination}

The presence of spores, structure of hyphae, features of aerial and substrate mycelium were determined by microscopic observation. The smear of isolate was prepared by adding $0.5 \mathrm{ml}$ of culture suspension to thin smear of YEME medium on a sterile Petri plate. The culture was spread gently over the solidified medium and was incubated at $28^{\circ} \mathrm{C}$ for 7 days. Morphological examination was then carried out at $100 \mathrm{X}$ magnification using Transmission Electron Microscope [32].

\subsubsection{Culture Characteristics}

The growth characteristics on different media, nutrients, physical conditions required for growth, were examined. Proper identification and characterization of microorganisms is very important because it expands the scope for exploitation of industrially important products. The isolate NDYS-4 was further identified by $16 \mathrm{~S}$ r-DNA sequencing, biochemical and culture characterizations [33].

\section{RESULTS AND DISCUSSION}

\subsection{Extraction of Humic Acid}

As per modified Essington method, black coloured shiny crystals were extracted from organic soil. Humic acid is soluble in sodium hydroxide and insoluble in water. The extracted crystals have passed this test, as shown in Fig-1, and were conformed as humic acid crystals. These humic acid crystals were used for screening of biosurfactant producing actinomycetes.

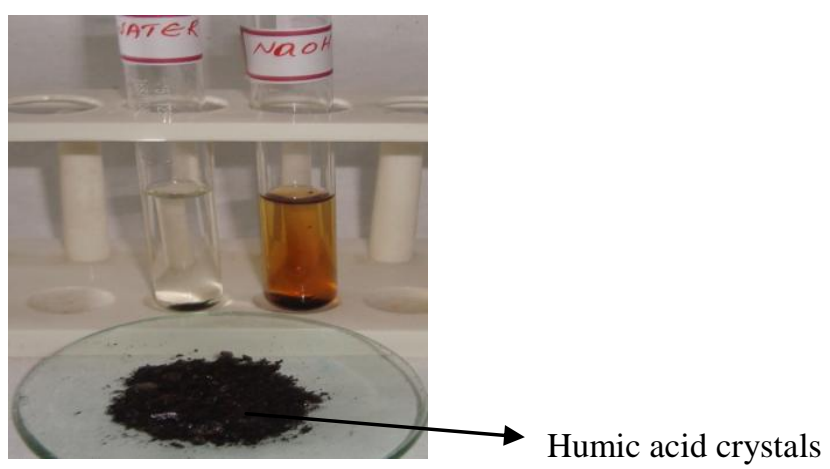

Fig-1: Identification test for humic acid and extracted humic acid crystals.

\subsection{Isolation and Screening of Biosurfactant Producing Actinomycetes}

A total of 10 strains of actinomycetes were isolated from oil contaminated naval dockyard soil named NDYS. All these isolates were initially screened for extracellular biosurfactant production grown on Kim's medium containing olive oil as sole source of carbon [21]. Out of these 10, only three isolates of NDYS, namely, NDYS-1, NDYS-3 and NDYS-4, had shown positive results for Oil spreading method [22]. As per the results observed for these three isolates, the drop displaced zone for NDYS-4 had shown maximum displaced area with a diameter of $8.5 \mathrm{~cm}$, indicating a good biosurfactant production. Again, these three isolates were tested for biosurfactant production by parafilm-M test, where a flat drop was shown by NDYS-4 taking sodium laryl sulphate as positive control and distilled water as negative control [23].

The biosurfactant activity of NDYS-1, NDYS-3 and NDYS-4, were evaluated by Emulsification index. The emulsification of these isolates were detected from the first day of incubation period, had shown that the highest of emulsion was formed at $72 \mathrm{~h}$ by NDYS-4, compared with the standard sodium laryl sulphate [34]. In order to identify the type of biosurfactant, phenol- $\mathrm{H}_{2} \mathrm{SO}_{4}$ test was performed with cell-free supernatant of NDYS. According to the method described by Dubois $\mathrm{M}$ et al, NDYS-4 isolate had shown orange colour when phenol and sulphuric acid were added. The orange colour indicated that the biosurfactant obtained was glycolipid in nature [26]. These results are shown in Table-1.

\subsection{Conformation Assay for Rhamnolipid}

In the present study, Orcinol assay was performed for the conformation of Rhamnolipid. According to Chandrasekher et $a l$, this test was conducted, and only NDYS-4 isolate had shown Rhamnolipid production [27]. This had confirmed that NDYS-4 isolate is a potential producer of glycolipids. The types of glycolipid were found to be Rhamnolipid in nature from the results shown in Table-1. Therefore, this isolate NDYS-4 was selected for quantification of Rhamnolipid by taking L-Rhamnose as standard. 
Table-1: Detection of biosurfactant producing actinomycetes

\begin{tabular}{|c|l|c|c|c|c|c|}
\hline S. No & \multicolumn{1}{|c|}{ Test } & Control & NDYS-1 & NDYS-3 & NDYS-4 & SLS \\
\hline 1 & Drop spreading test & - & $2.5 \mathrm{~cm}$ & $4 \mathrm{~cm}$ & $8.5 \mathrm{~cm}$ & $10 \mathrm{~cm}$ \\
\hline 2 & Parafilm-M test & - & + & + & +++ & +++ \\
\hline 3 & Emulsification index & - & $20.21 \%$ & $23.47 \%$ & $52.43 \%$ & $57.31 \%$ \\
\hline 4 & Phenol $\mathrm{H}_{2} \mathrm{SO}$ 4 test & - & - & - & + & - \\
\hline
\end{tabular}

(1) Diameter of zone of oil displaced in ' $\mathrm{cm}$ ' (2) (+) spreading of drop, (-): dome shape (3) Emulsification index in '\%' (4) $\mathrm{Phenol}_{-} \mathrm{H}_{2} \mathrm{SO}_{4}$ test (+): orange colour to yellowish orange

\subsection{Bioautography}

By performing the bioautography for cell-free supernatant of NDYS-4, the bioactive compound was found to be antibiotic. Significant inhibition zones were observed against Escherichia coli, as shown in Fig-2.

\subsection{Antimicrobial Activity}

The isolates of actinomycetes were tested for microbial sensitivity against Gram positive and Gram negative bacterial strains by Cup plate method. The biosurfactant isolated from NDYS-4 by acid precipitation method, had shown significant activity against E.coli and S.aureus, and significant zones of inhibition were observed [31].

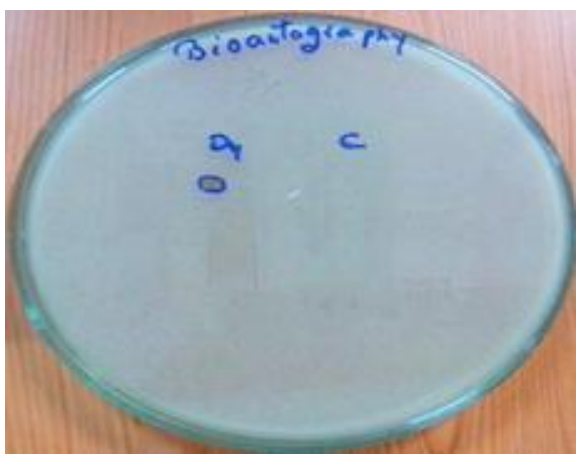

Fig-2 Bioautography of NDYS-4 against bacterial test organism

\subsection{Time Course of Biosurfactant Production and}

\section{Antimicrobial Activity}

The biosurfactant production was dependent on growth of culture in the fermentation medium at about $3^{\text {rd }}$ day of growth, surfactant concentration started to increase, reaching its maximum after about $7^{\text {th }}$ day. As antimicrobial activity depends on the concentration of Rhamnolipid, maximum activity was observed on $7^{\text {th }}$ day.

The decrease in antimicrobial activity after $8^{\text {th }}$ day of incubation had shown that the biosurfactant biosynthesis had stopped, and was probably due to the production of secondary metabolites. This indicated that the biosurfactant production had occurred predominantly in the exponential growth phase, suggesting that the biosurfactant produced was primary metabolite as shown in Fig.3 [29]. 


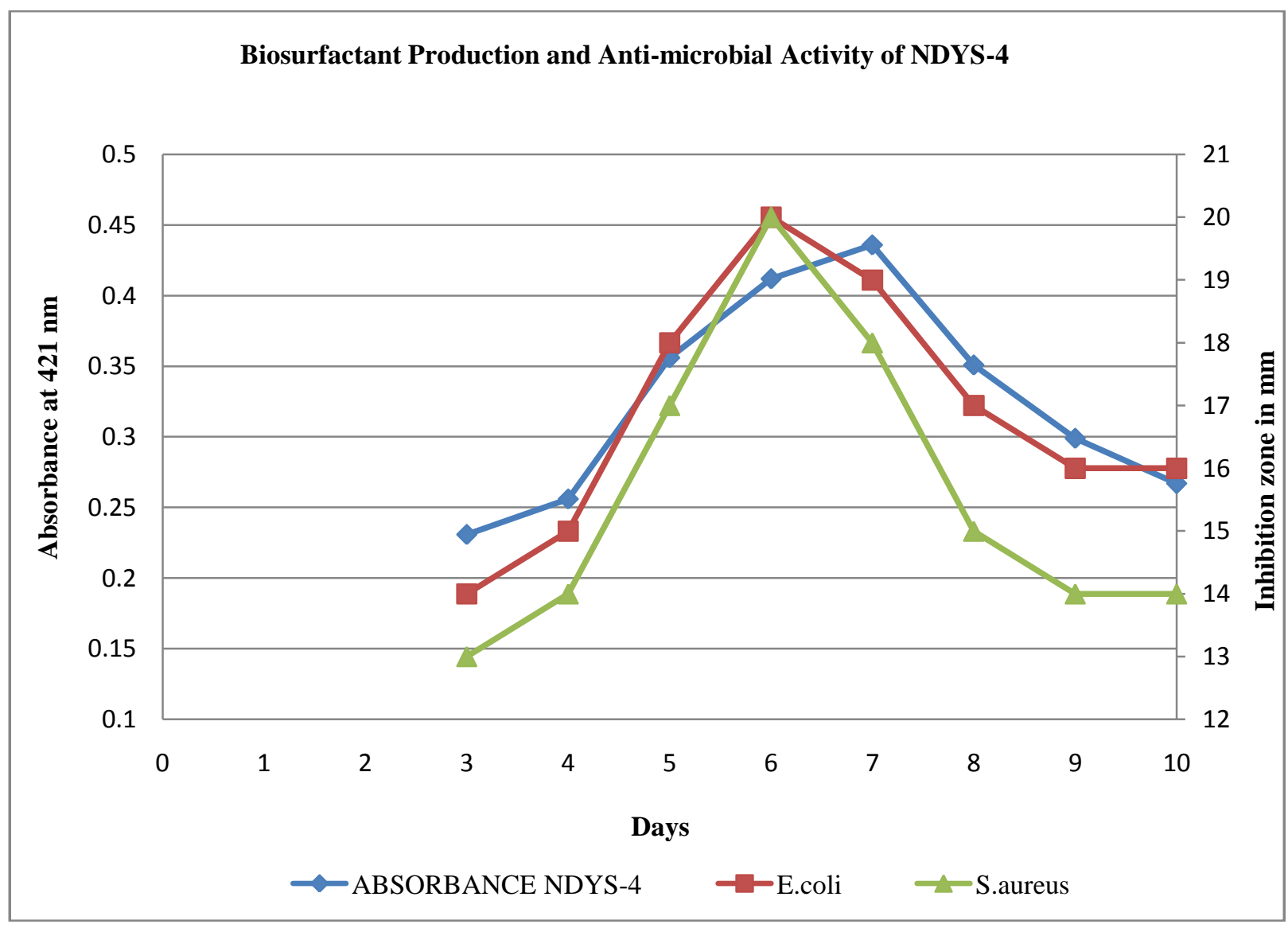

Fig-3 Biosurfactant Production and Antimicrobial Activity of NDYS-4

\subsection{Characterization of Strain NDYS-4}

The strain NDYS-4 had shown promising growth in Kim's medium using olive oil as sole source of carbon at temperature range of $28{ }^{0} \mathrm{C}$ for 7 days. Outer surface of colonies were perfectly round initially, but later developed thin wavy mycelium. The colour of the aerial mycelium observed was white and the colour of the substrate mycelium was pink. By studying the morphology and 16S rDNA sequencing (Fig-4), the isolated strain was found to be Streptomyces coelicoflavus.

The screened isolate of NDYS-4 was sent to IMTECH, Chandigarh, INDIA, for the analysis of the Phylogenetic tree and nomenclature of the strain, as shown in Fig-4. In this figure, the numbers at the nodes indicate the levels of bootstrap support (\%), based on neighbour-joining analysis of 1000 resample datasets, and values more than $50 \%$ only are given. IMTECH accession numbers are given in parentheses.

\section{CONCLUSIONS}

In the present study, Streptomyces coelicoflavus isolated from oil contaminated Naval dockyard soil, had shown significant biosurfactant activity. The importance of this biosurfactant for industrial use was proven by its physical properties like emulsification. The functional characterization of this isolated biosurfactant had indicated that the biosurfactant produced was Rhamnolipid in nature, which belongs to glycolipids class. The isolated biosurfactant had shown significant antibacterial activity.

\section{ACKNOLEDGEMENTS}

The author expresses her gratitude to Prof. G. Girija Sankar and Prof. T. Prabhakar (A.U. College of Pharmaceutical Sciences) for their immense help and valuable advises for this research work. 


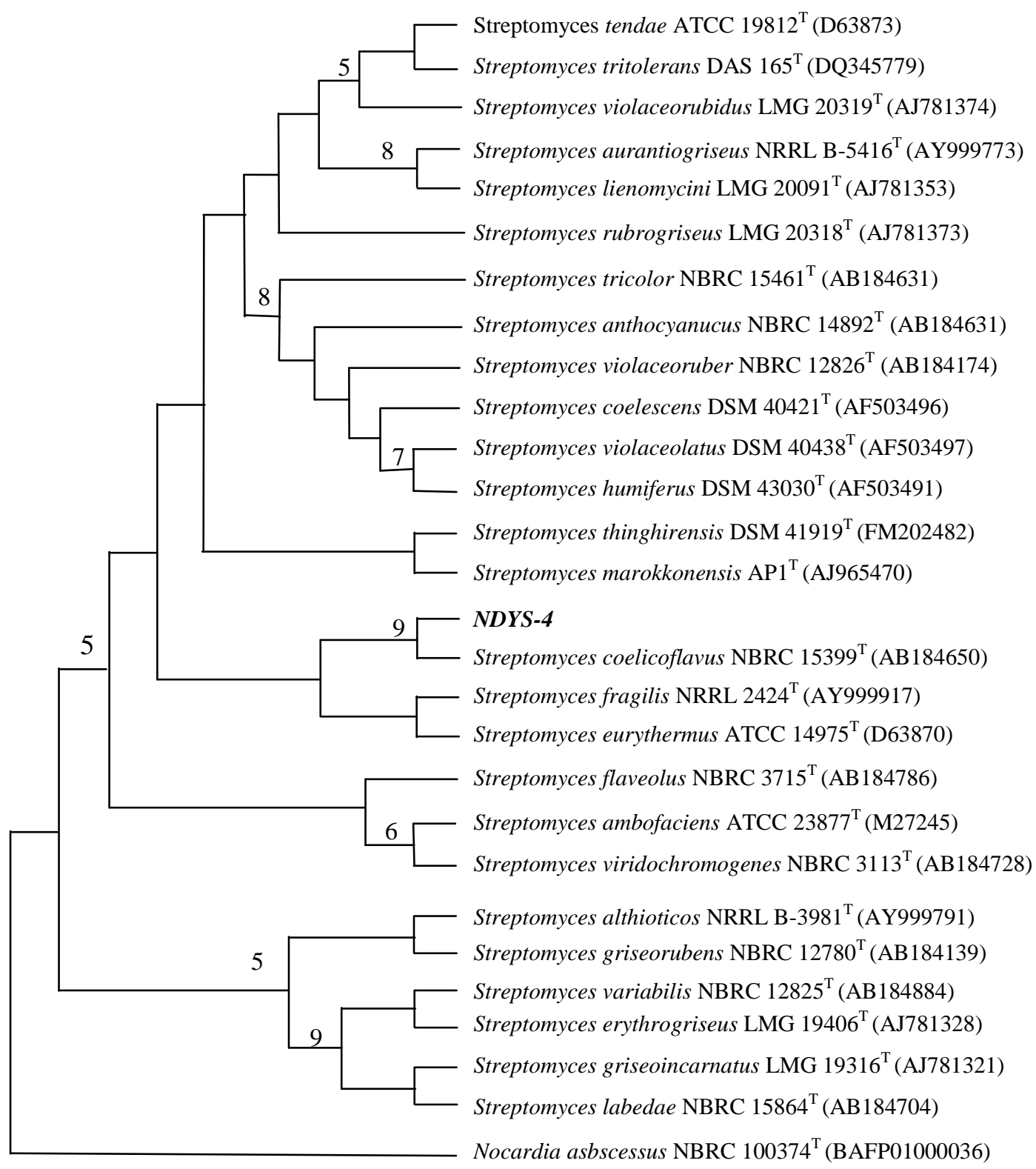

Fig-4: Neighbour-joining Phylogenetic Tree of strain NDYS-4 made by IMTECH, Chandigarh, India.

\section{REFERENCES}

[1]. Stevenson, F.J. 1994. Humus Chemistry Genesis: Composition, Reactions. Vol 2. $2^{\text {nd }}$ edition. New York. John Wiley and Sons: 291-497.

[2]. Saikh, H. and Chandra, P.K. 1999. Some Characteristics of soil humic substances of entisol, alfisol and vertisol. $J$. Indian Soc Soil Sci. 47:206-211.

[3]. Karanth, N.G.K., Deo, P.G. and Veenanadig, N.K. 1999. Microbial production of biosurfactants and their importance. Curr Sci. 77:116-126.

[4]. Costa, S.G.V.A.O., Nitschke, M., Haddad, R., Eberlin, M. and Contiero, J. 2006. Production of Pseudomonas aeruginosa
LB1 Rhamnolipids following growth on Brazilion native oils. Process Biochem. 41:483-488.

[5]. Mulligan, C.N. and Catherine, N. 2005. Environmental application for biosurfactants. Environ Pollut. 133:183-198.

[6]. Volkering, F., Breure, A.M. and Rulkens, W.H. 1998. Microbiological aspects of surfactant use for biological soil remediation. Bio-degradation. 8:401-417.

[7]. Mulligan, C.N., Yong, R.N. and Gibbs, B.F. 2001. Surfactant-enhanced remediation of contaminated soil: a review. Eng.Geol. 60:371-380.

[8]. Falatko, D.M. and Novak, J.T. 1992. Effect of biologically produced surfactants on the mobility and biodegradation of petroleum hydrocarbons. Water Environ Res. 64(2):163-169. 
[9]. Banat, I.M., Makkar, R.S. and Cameotra, S.S. 2000. Potential Commercial applications of microbial surfactants. Appl Microbiol Biotechnol. 53:495-508.

[10]. Desai, J.D. and Banat, I.M. 1997. Microbial production of surfactants and their commercial potential. Microbiol. molecular biol reviews. 61(1):47-64.

[11]. Arutchelvi, J.I., Bhaduri, S., Uppara, P.V. and Doble, M. 2008. Mannasy lerythritol lipids: a review. J Ind Microbiol Biotechnol. 35:1559-1570.

[12]. Maier, R.M. and Soberon, C.G. 2000. Pseudomonas aeruginosa rhamnolipids, biosynthesis and potential application. J Appl microbiol and biotechnol. 54(5): 625-633.

[13]. Ochoa-Loza, F.J., Artiola, J.F. and Maier, R.M. 2001. Stability constants for the complexation of various metals with a rhamnolipid biosurfactant. J Environ Quality. 30:479-485.

[14]. Liang, M.W., Pao-Wen, G.L., Chih-Chung, M. and Sheng-Shung, C. 2008. Application of rhamnolipid and surfactin for enhanced diesel biodegradation effects of $\mathrm{pH}$ and ammonium addition. J Hazardous Materials. 51(1):63-155.

[15]. Kosaric, N. 2001. Biosurfactants for soil Bioremediation. Food Technol. Biotechnol. 39:295-304.

[16]. Wouter, H., Noordman., Dick, B. and Jansen. 2002. Rhamnolipid stimulates uptake of Hydrophobic compounds by Pseudomonas aeruginosa. Appl. Environ Microbiol. 68(9):4502-4508.

[17]. Anand, S., Nayaka, M.H., Vijaykumara, and Karegoudar, T.B. 2009. Characterization of biosurfactant produced by Pseudoxanthomonas sp. PNK-04 and its application in bioremediation. Int. J. Biodeterioration and Biodegradation. 63(1):73-79.

[18]. Haykawa, M. and Nonomura, H. 1987. Humic acidvitamin agar: A new medium for selective isolation of soil actinomycetes. Ferment Technol. 65:501-509.

[19]. Intira, T., Naowarat, C., Wasu, P.A., Pimporn, L. and Saisamorn, L. 1987. Isolation and Identification of Biosurfactant producing Actinomycetes From Soil. Res. J. Microbiol. 3:499-507.

[20]. Nuttawan, Y., Woranart, J., Nawaphorn, K. and Ranjna, J. 2010. Degradation of Humic Acid in Soil Aqueous Extract Using the Fenton Reaction and a Microbiological Technique. Kasetsart J. (Nat. Sci.). 44:1069-1078.

[21]. Kim, S.H., Lim, E.J., Lee, T.H. and Korean. 1998. Purification and characterization of biosurfactants from Nocardia sp. L-417. Soc. Food Sci. Nutr. 27:252-258.

[22]. Morikawa, M., Hiratr, Y. and Imanaka, T.A. 2000. Study on the structure-function relationship of lipopeptide biosurfactants. Biochem Biophys Acta. 1488(3):211-218.

[23]. Youssef, N.H., Duncan, K.E., Nagle, D.D., Savage, K.H., Knapp, R.M. and McInerney, M.J. 2004 Comparison of methods to detect biosurfactant production by diverse microorganisms. J. Microbiol. Methods. 56:339-347.

[24]. Satpute, S.K., Bhawsar, B.D., Dhakephalkar, P.K. and Chopade, B.A. 2008. Assessment of different screening methods for selecting biosurfactant producing marine bacteria. Indian J. Mar. Sci. 37(3):243-250.
[25]. Surachai, T., Pimporn, L., Dammrong, S. and Lumyong, S. 2007. Preliminary screening of biosurfactant producing microorganisms isolated from hot spring and garages in northern Thailand. KMITL J. Sci. Technol. 7:38-43.

[26]. Ellaiah, P., Prabhakar, T., Sreekanth, M., Thaer-Taieb, A., Bhima-Raju, P. and Saisha, V. 2002 Production of glycolipids containing biosurfactant by Pseudomonas sp. Indian J. Exp. Biol. 40:1083-1086.

[27]. Chandrasekaran, E.V. and Bemiller, J.N. 1980. Constituent analyses of glycosaminoglycans. In Methods in Carbohydrate Chemistry. Academic Press. New York: Whistler, R.L. ed.89-96.

[28]. Nelly, C., Borjana, T., Zdravko, L., Albena, J. and Bojidar, J. 2004. Rhamnolipid biosurfactant produced by Renibacterium salmoninarum $27 \mathrm{BN}$ during growth on nHexadecane.Z. Naturforsch. 59:70-74.

[29]. Kokare, C.R., Kadam, S.S., Mahadik, K.R. and Chopade, B.A.2007. Studies on bioemulsifier production from marine Streptomyces sp. S1. Indian J. Biotechnol. 6:78-84.

[30]. Ahmad, R.M.Y., Salwa, M.S. and Nur-Asshifa Md, N. 2011. Comparative study: Different recovery techniques of rhamnolipid produced by Pseudomonas aeruginosa USMAR2. International Conference on Biotechnology and Environment Management. 18:24-30.

[31]. Cappucino, J.G. and Sherman, N. 1999. Microbiology: A Laboratory Manual. Volume 4. C. Edition. Addison Wesley. Longman, Inc. Harlow, England. Cripps. 199-204.

[32]. Chakraborty, S. Khopade, A., Kokare, C., Mahadik, K. and Chopade, B. 2009. Isolation and characterization of noval $\alpha$-amylase from marine Streptomyces sp. D1. J. Mol. Catal. B: Enzym. 58:17-23.

[33]. Margalith, Beretta and Timbal. 1959. Type strain: ME/17 (i bid.), ISP 5188 from LG Silvestri, Lepetit S P A, as Lep. M-ME/17: ISP description by Group A-13:71-75.

[34]. Saharan, B.S., Sahu, R.K. and Sharma, D. 2011. A Review on Biosurfactants: Fermentation, Current Developments and perspectives. Genetic Engineering and Biotechnol J. GEBJ-29:1-14.

\section{BIOGRAPHIES}

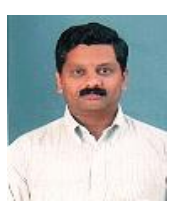

Prof. G. Girija Sankar is the Head of the Pharmaceutical Biotechnology Department at A.U College of Pharmaceutical Sciences, Andhra University, Visakhapatnam, Andhra Pradesh, India.

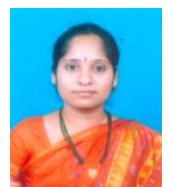

Mrs. Kalyani A.L.T is a Research Scholar at A.U College of Pharmaceutical Sciences, Andhra University, Visakhapatnam, Andhra Pradesh, India. 
Ms. Naga Sireesha G is an M.Pharm student at A.U College of Pharmaceutical Sciences, Andhra University, Visakhapatnam, Andhra Pradesh, India.

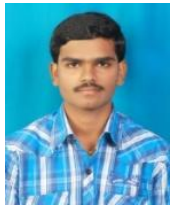

Mr. Aditya A.K.G is an M.Pharm Student at A.U College of Pharmaceutical Sciences, Andhra University, Visakhapatnam, Andhra Pradesh, India 